\title{
البيان الثمتامي
}

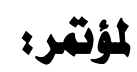

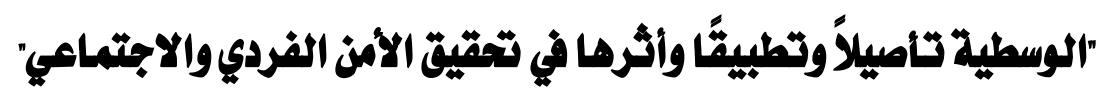

إنه في يوم الثلاثاء الموافق الثامن والعشرسين من شـهر ســبتمبر عام ألفين وإحدى وعشر-ين

للميلاد الموافق الحادي والعشرين من شهر صفر عام ألف وأربعجائة وثلاث وأربعين للهجرة. انعقد المؤتمر الدولي الأول لكلية الدراسـات الإسـلامية والعربية للبنين بالشر-قية بالتعاون مع

كلية الدراسات العليا.

وقد بلغ عدد الأبحاث المشاركة أربعةً وخمسين بحثَّ، وبلغ عدد الدول المشاركة ثمان دول هي: مصر، الأردن، العراق، السعودية، الإمارات، السودان، ماليزيا، الصين،. وإن إدارة المؤتمر وكلية الدراسـات الإسـلامية والعربية للبنين بالديدامون شرقية، وكلية الدراسـات العليا، والمشــاركين في المؤتمر والحضــور، ليثمنون لفضــلة الإمام الأكبر أد. أحمد محمد الطيب، شـيخ الأزهر، ولفضـيلة الأسـتاذ الدكتور: محمد عبد الرحمن الضــويني، وكيل الأزهر، ولمعالي الأستاذ الدكتور: محمد حسين المحرصاوي، رئيس جامعة الأزهر، وللسادة أصحاب المعالي النواب، جميعا، والسـادة العمداء ولكل من سـاهم في انعقاد هذا المؤتمر من قريب أو بعيد، والذي يعد ضرورةً آنيَّةَ لدورهم البارز في انعقاد هذا المؤتمر. وفي ختام هذا اليوم الحالفل وما نوقش فيه من بحوث متعددة بلغت أربعة وخمسـين بحثا، في تخصـصـات الشر-يعة الإسـلامية، وأصــول الدين، واللغة العربية، وعلم الاجتحاع، وعلم النفس، والدراسـات الإسـلامية، وغيرها، يمكن آن تخرج بوثيقة تجمع أهم ما جاء خلال هذه البحوث من توصيات يمكن عرضها في النقاط التالية: 
أولا : ضرورة تكثيف الجهود لتحديد مضامين الفكر الوسطي بعيدًا عن الغلو أو التفريط، وتجدر الإثــارة هنا إلى الجهود الكبيرة التي بذها ويبذهاصـاحب الفضــلة شـيخ الأزهر في رفع ثـعار الوسطية والاعتدال وذلك للم شمل أفراد أبناء الأمة. ثانيا: علينا آن نعالج مشكلات المجتمع المعاصرة بروية وسطية وبروية دون انفعال. ثالثا-علينا جميعا وعلنى الباحثين بوجه خاص آن يقوموا بتصحيح المفاهيم المغلوطة عن الاسلام وأحكامه من خلال بيان تعاليم الكتاب والسـنة والدعوة للوسـية سـلوكًا ومنهجا والتحذير من الغلو والإفراط .

رابعا-علينا التصـدي لتيارات الغلو والتطرف وتوضـيح جنايتها علئصسحيح الإسـلام. وآن نغرس ثقافة الوســية بين الطلاب والطالبات في مراحل التعليم المختلفة حتىل نحصـن الشـباب وننأي بهم عن الوقوع في براثن المضللين والمنحرفين. خامسا :على المتصدي للدعوة أن يتتبه من تحريف المغالين وانتحال المبطلين وتأويل الباهلين. ســادسـاء يهيب المؤتمر بالعلماء والدعاة وأساتذة الجامعات ورجال التربية والإعلام لبذل جهد جماعي منسق لفضح افتراءات المتطرفين وكشف شبهاتهم وتعريف الناس بزيف شعاراتهم وبطلان دعاويهr. ســـابعا : تعزيز الحطاب الو سطي، وتقديم روية إسلامية عميقةَ تكون كالمصل الذي يقي من الفيروسات الخبيئة والأوبئة المهلكة. ثامنـا ضرورة تأهيل الدعاة والنابين لمعرفة كيفية معالجة ما يجد في المجتمع من مشـكلات بروية تتسم بالاعتدال والوسطية. 
تاســا : ضرورة وضع خطة استراتيجية شاملة ومنكاملة لمواجهة كل ا شكال التطرف لضمان

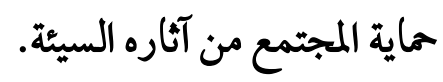
عاثــرا-أهمية الثدريب للأمة وعلماء الدين من الشباب علئ استخدام الإرشاد النفسي الديني المبني على التسامح وقيم الوسطية من أجل تحقيق الطمأنينة النفسية وخاصة لدئ الشباب. حادية عشرة- العمل بجميع الوسائل الممكنة والمتاحة علئ مواجهة التيارات المدامة والدعوات المعادية للإسـلام، والأخطار الثقافية داخليا وخارجيا، بنشر- الفكر الوسـي الذي يخدم القضــايا المختلفة للأمم.

ثانية عشرة- العمل علئ مواجهة الغلو في الدين والانحراف في تأويل نصوصه، بـا تمليه وسطية الإسلام، وسماحته وشموله: عقيدة وشريعة وعبادة ومعاملة وفكرا وسلوكا. ثالثة عشـر- بناء منظومة عالمية للعلم) الموثوقين لتشكيل هيئة عالمية ومتتدئ دوليّ للو سطية، تُعنَي بتوضـيح مفاهيم الوسـية وكيفية تحقيقها بين أفراد الأمم ومؤسسـاتها، وتعزيز قدراتها على القيام بدورها الحضاري وأمنها الفردي والاجتاعي. رابعة عشر-ضرورة انعقاد مثل هذا المؤتمر بصفة دورية كل ثلاث سنوات علئ الأكثر. وفي ختام هذا المؤتمر لا يسـعنا إلا أن ندعو الله -عز وجل - أن ييزي القائمين على هذا المؤتم

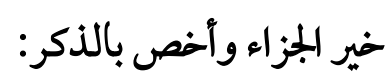
صـاحب الفضـل والفضـيلة الإمام الأكبر: أد. أمدم محمد الطيب، شـيخ الأزهر، وصـاحب الفضيلة معالي رئيس الجامعة، وأصحاب المعالي السادة النواب، والسادة العمداء الذين لميال جهدًا في إخراج هذا المؤتمر على الوجه اللائق به. كما أتقدم بالشكر لكل من شرفنا بالمشاركة أو الحضور أو التنظيم في هذا المؤتمر. 
كما آتوجه بخالص الشكر والتقدير لجميع الأساتذة المحكمين، والسادة الأساتذة الذين قاموا على رئا سة الجلسات العلمية، ولجميع أبنائنا النابين من الباحثين والباحثات الذين ساهموافي إثراء هذا المؤتمر.

كما أ شكر كل من شاركنا بالمخور وكان له دور فعَّال بالمناقشة والتوجيه، لكم منا جميعا كل الشكر والتقدير والامتنان علن ما بذلتم من جهد. وختامًا ندعو الله-عز وجل - أن يففظ قائد البلاد المفدئ فخامة الرئيس: عبد الفتاح السيسي. الذي يوجه دائًا إلى العمل على نشر-ثقافة الوسطية والالتفاف حول راية الوطن والانتحاء إلى ترابه، والمحافظة علن كرامة المصري، وآن يجيا حياة كريمة كما ندعو الله-عز وجل - أن يففظ بلدنا للمبيب مصر، وأن تنعم ريوعها داتَّا بالأمن والأمان. وأن يوفق أصسحاب المعالي السـادة الوزراء، وآن يسـدد خطاهم، وأن يمدهم بمدد من عنده لدعمهم المستمر للعلم والعلماء، كما ندعوه سـبحانه أن يجفظ أبناء الوطن وأن ييعلهمصـفّا واحدًا وعلئ قلب رجل واحد في وجه كل متربص وخائن. ولا ننســ رجال الأمن الذين يتواصـلون معناليل نهار لإنجاح هذا العمل العلمي، لكم منا جميعا خالص الشكر ووافر الامتنان.

وآخر دعوانا أن الحمد لله رب العالمين. وصلّ اللهم وسلم ويارك على سيدنا محمد وعلى آله وصحبه أجمعين. 